\title{
Toxicidade de produtos fitossanitários utilizados em citros para Apis mellifera
}

\author{
Toxicity of pesticides used in citrus crop to Apis mellifera
}

\author{
Ana Paula Machado Baptista ${ }^{\text {* }}$ Geraldo Andrade Carvalho ${ }^{\mathrm{I}}$ Stephan Malfitano Carvalho \\ César Freire Carvalho ${ }^{\mathrm{I}}$ Júlio Sílvio de Souza Bueno Filho ${ }^{\text {II }}$
}

\section{RESUMO}

\begin{abstract}
O objetivo deste trabalho foi avaliar a toxicidade de inseticidas/acaricidas utilizados em cultura de citros para operárias africanizadas de Apis mellifera Linnaeus. A exposição das abelhas aos compostos foi realizada usando-se técnicas de pulverização, contaminação da dieta e contato em superfícies tratadas (folhas de citros e placas de Petri), empregando-se as doses máximas recomendadas para a cultura. Os bioensaios foram realizados em laboratório a $25 \pm 2{ }^{\circ} \mathrm{C}$, UR $70 \pm 10 \%$ e fotofase de $12 \mathrm{~h}$, sendo os dados de mortalidade submetidos à análise estatística, e as médias comparadas por contraste, obtendo-se grupos de efeitos semelhantes. Independente do modo de exposição, o acefato foi extremamente tóxico, matando mais de 90,0\% das abelhas 24 h após a aplicação. Os produtos espirodiclofeno e piriproxifem, quando aplicados diretamente sobre as abelhas, causaram níveis de mortalidade de $11,0 \mathrm{e}$ $15,0 \%$, respectivamente; os compostos buprofezina, enxofre e tetradifona apresentaram níveis de mortalidade ainda menores, com média de 5,0\% entre eles. Para os ensaios de contaminação de superfície (folhas de citros e placas de Petri) e contaminação de alimento, foram obtidos dois grupos de toxicidade, um grupo somente com acefato e outro, com buprofezina, enxofre, espirodiclofeno, piriproxifem, tetradifona e água. A mortalidade média para esse segundo grupo, após $96 h$ do início da exposição, foi de 31,0; 8,3 e 15,7\%, respectivamente, para cada método de contaminação.
\end{abstract}

Palavras-chave: abelha africanizada, laranja, pesticida, mortalidade.

\section{ABSTRACT}

The aim of this research was to evaluate the toxicity of several acaricides/insecticides used in Brazilian citrus crop to africanized workers of Apis mellifera Linnaeus. The exposition of honey bees to the chemicals was performed by direct spraying, contamination of food, and contact in treated surface (citrus leaves and Petri dishes), using recommended rates of application. The assays were carried out at $25 \pm 2{ }^{\circ} \mathrm{C}, \mathrm{RH}$ $70 \pm 10 \%, 12 \mathrm{~h}$ of photophase and the data was statistically analyzed, with mean values of mortality being compared through cluster analysis. In all assays acephate was highly toxic, with mortality at 24 hours around 90.0\%. When spirodiclofen and pyriproxyfen, was sprayed directly into the honeybees, they caused mortality levels of 11.0 and $15.0 \%$, respectively; buprofezin, sulphur and tetradifon were less toxic, with mean mortality of $5.0 \%$ among these compounds. For the assays from contamination surface (citrus leaves and Petri dishes) and food, two groups of chemicals with the same toxic effects were observed, one with acephate and other with buprofezin, sulphur, spirodiclofen, pyriproxyfen, tetradifon and water. The average mortality after 96 hours of exposition was 31.0 ; 8.3 and $15.7 \%$, respectively, for each method of contamination.

Key words: africanized honey bee, orange, pesticide, mortality.

\section{INTRODUÇÃO}

O interesse na manutenção de abelhas em pomares citrícolas deve-se ao fato de elas serem consideradas importantes agentes polinizadores, contribuindo para o aumento de produção (MALERBOSOUZA et al., 2003; SANFORD, 2003a), além de serem responsáveis pela produção de mel, cera, geléia real e própolis (WIESE, 2005).

'Departamento de Entomologia, Universidade Federal de Lavras (UFLA), CP 3037, 37200-000, Lavras, MG, Brasil. Email: anapaula.ento@gmail.com.*Autor para correspondência.

"Departamento de Ciências Exatas, UFLA, Lavras, MG, Brasil 
O uso indiscriminado de produtos fitossanitários na cultura de citros é um dos fatores responsáveis pela diminuição na densidade populacional desse grupo de insetos, redução na produção e contaminação dos produtos de origem apícola (BELZUNCES et al., 1992; DEVINE et al., 2007). THOMPSON (2003) relatou que produtos fitossanitários, quando aplicados sobre adultos de abelhas, podem provocar a morte, repelência e interferência na capacidade de forrageamento e no desenvolvimento da colônia. DECOURTYE et al. (1995) verificaram que os inseticidas deltametrina, fipronil e dimetoato afetaram de forma negativa a capacidade de aprendizagem das abelhas Apis mellifera Linnaeus, com reflexos na distensão da probóscida. Também estudando o efeito de deltametrina sobre essa mesma espécie de inseto, VANDAME et al. (2005) observaram que adultos contaminados com esse composto apresentaram movimentos descoordenados, distúrbios no senso de direção e comprometimento quanto à capacidade de retorno à colônia.

A maioria dos estudos visando a avaliar os efeitos de produtos fitossanitários sobre abelhas tem sido realizada com espécies européias, as quais geralmente mostram-se suscetíveis aos efeitos tóxicos de compostos empregados para o controle de pragas em culturas de importância econômica (DEVILLERS \& PHAM-DELEGUE, 2002). No Brasil, pesquisas a respeito do impacto de compostos sobre abelhas africanizadas são escassas, assim é preciso que novos trabalhos sejam desenvolvidos a fim de se conhecer a interação abelhas e produtos químicos.

Assim, o objetivo desta pesquisa foi avaliar os efeitos de produtos fitossanitários empregados em cultura de citros sobre adultos de abelhas africanizadas por meio de técnicas de pulverização direta, ingestão de alimento contaminado e contato em folhas de citros e placas de vidro tratadas.

\section{MATERIAL E MÉTODOS}

Para realização dos bioensaios, foram utilizadas operárias forrageadoras de A. mellifera africanizadas, coletadas em quadros de melgueira, em colônia do Apiário Central da Universidade Federal de Lavras - UFLA. As operárias foram transportadas em gaiolas teladas para laboratório.

Avaliou-se a toxicidade dos produtos fitossanitários (g ou $\mathrm{mL}$ p.c. $100 \mathrm{~mL}^{-1}$ ): espirodiclofeno (Envidor 240 CS - 0,025), tetradifona (Tedion $80 \mathrm{EC}$ 0,3), buprofezina (Applaud $250 \mathrm{WP}$ - 0,2), piriproxifem (Cordial 100 EC - 0,075), enxofre (Kumulus 800 WG $0,5)$ e acefato (Orthene $750 \mathrm{BR}-0,075$ ). As abelhas foram submetidas aos produtos usando-se técnicas de pulverização direta, fornecimento de dieta contaminada e contato em superfícies tratadas. Como testemunhas negativas, foram utilizadas água destilada nos bioensaios de pulverização e de contato em superfícies tratadas e pasta Cândi pura nos bioensaios de contaminação do alimento.

No ensaio de pulverização, os produtos foram aplicados diretamente sobre as abelhas utilizando-se pulverizador manual à pressão contínua com aplicação de $1,5 \pm 0,5 \mu \mathrm{L} \mathrm{cm}^{-2}$. Em seguida, os insetos foram transferidos para gaiolas cilíndricas de PVC de $15 \mathrm{~cm}$ de diâmetro e $10 \mathrm{~cm}$ de altura, sendo vedadas com tecido branco do tipo filó. O alimento fornecido às abelhas constituiu-se de pasta Cândi colocada sobre o filó e um pedaço de algodão embebido em água destilada.

Para o ensaio de fornecimento de alimento contaminado, os compostos foram incorporados ao mel empregando-se a dosagem calculada em função da relação peso/volume e, em seguida, adicionou-se açúcar de confeiteiro para preparação da pasta Cândi, obtendo uma dieta homogênea. Depois de anestesiadas com $\mathrm{CO}_{2}$ durante 120 segundos, as abelhas foram colocadas dentro de gaiolas de PVC, e a pasta Cândi contaminada com os respectivos produtos foi colocada sobre o filó, além de chumaço de algodão embebido em água destilada, o qual foi umedecido periodicamente para evitar ressecamento.

No ensaio de contato em superfície vítrea contaminada, utilizaram-se arenas constituídas de duas placas de Petri de $10 \mathrm{~cm}$ de diâmetro e $2 \mathrm{~cm}$ de altura, dispostas uma sobre a outra e fixadas por grampos metálicos colocados eqüidistantes em sua borda. As placas foram submetidas à pulverização com os produtos por meio de torre de Potter regulada à pressão de $15 \mathrm{lb} \mathrm{pol}^{-2}$, aplicando-se $1,5 \pm 0,5 \mu \mathrm{L} \mathrm{cm}^{-2}$. Após a secagem das placas por aproximadamente uma hora, realizou-se a montagem das arenas onde abelhas anestesiadas com $\mathrm{CO}_{2}$ foram distribuídas. Em cada placa de Petri foi colocado um recipiente plástico de $2 \mathrm{~cm}$ de diâmetro e $5 \mathrm{~mm}$ de altura contendo pasta Cândi. No experimento usando folhas de citros contaminadas, plantas de tangerina Ponkan Citrus reticulata Blanco isentas de qualquer tratamento fitossanitário foram escolhidas, sendo as folhas tratadas por meio de imersão nas respectivas caldas químicas por um período de cinco segundos. Após secagem por aproximadamente uma hora, as folhas em número de quatro por arena foram fixadas pela superfície abaxial usando-se fita adesiva de dupla face. De modo semelhante ao dos ensaios anteriores, as abelhas foram anestesiadas e colocadas em número de 10 por arena, recebendo como alimento pasta Cândi. 
Os experimentos foram realizados a $25 \pm 2^{\circ} \mathrm{C}$, UR $70 \pm 10 \%$ e fotofase de $12 \mathrm{~h}$. O delineamento foi inteiramente casualizado com 10 repetições para os bioensaios de pulverização e dieta contaminada e cinco repetições para os de contato com superfícies tratadas, empregando-se em cada unidade experimental 10 operárias adultas. A mortalidade dos adultos foi avaliada a uma; duas; três; quatro; cinco; seis; nove; $12 ; 15 ; 18 ; 21 ; 24 ; 30 ; 36 ; 42 ; 48 ; 60 ; 72$ e 96 horas após o início da exposição das abelhas aos produtos. Para cada bioensaio, os dados obtidos foram submetidos à análise de sobrevivência, usando o pacote Survival do software $\mathrm{R}^{\circledR}$ (2008). Após a seleção do modelo matemático mais adequado por meio da análise de resíduos, realizou-se a análise de contraste para verificar a semelhança entre os produtos testados e a formação de grupos congêneres. Também foram calculados os tempos letais $50\left(\mathrm{TL}_{50}\right)$ para cada grupo formado.

\section{RESULTADOS E DISCUSSÃO}

Efeito da pulverização direta dos produtos sobre $\boldsymbol{A}$. mellifera

Observou-se que acefato foi altamente tóxico para as abelhas, pois, após 40 horas de sua aplicação, causou mortalidade de quase todos os insetos, apresentando $\mathrm{TL}_{50}$ de 14,41 horas. Espirodiclofeno e piriproxifem provocaram mortalidade de aproximadamente $10 \%$ ao término das avaliações com $\mathrm{TL}_{50}$ de 466,38 horas, e buprofezina, enxofre e tetradifona foram inócuos com $\mathrm{TL}_{50}$ estimado de 1.122,15 horas (Figura 1A, Tabela 1).

Ressalta-se que acefato causou sintomas de intoxicação logo após o início da contaminação, tais como falta de coordenação motora, tremores e prostração, fazendo com que as abelhas permanecessem no fundo das gaiolas. Esses efeitos, segundo RIGITANO \& CARVALHO (2001), são característicos de produtos organofosforados, os quais se acoplam à enzima acetilcolinesterase, não permitindo a degradação da acetilcolina e, conseqüentemente, induzindo impulsos nervosos repetitivos. Os resultados obtidos com acefato confirmam aqueles de ATKINS et al. (1981) e STONER et al. (1985), os quais verificaram alta toxicidade desse composto para operárias de abelhas. Utilizando doses subletais desse composto, STONER et al. (1985) constataram resíduos em diferentes partes do corpo de abelhas e na geléia real produzida até nove dias de sua aplicação. DAVY et al. (2007) relataram que acefato pode ser mais tóxico às abelhas e aos inimigos naturais do que aos próprios insetos-praga.
A inocuidade dos inseticidas reguladores de crescimento piriproxifem e buprofezina avaliados no presente estudo pode estar relacionada ao modo de ação dos inseticidas, visto que piriproxifem é análogo do hormônio juvenil e buprofezina é inibidor da síntese de quitina, portanto afetando os insetos em suas fases jovens. ROBINSON (2001) relatou a baixa toxicidade de buprofezina a alguns grupos de insetos benéficos, constatando-se inocuidade desse produto para ovos, larvas, pupas e adultos de abelhas na dosagem de $25 \mathrm{~g}$ i.a. $100 \mathrm{~L}^{-1}$ de água. Piriproxifem foi relatado por DEVILLERS et al. (2003) como um produto seguro e de baixa toxicidade para abelhas adultas. No entanto, OUTLAW et al. (2006) e RIEDL et al. (2006) recomendaram que sua aplicação deve ser realizada em épocas de não ocorrência de abelhas, preferencialmente após o período de floração.

A inocuidade de tetradifona observada no presente trabalho confirma os resultados encontrados por ANDERSON \& ATKINS (1968), que o classificaram como sendo um produto de baixa toxicidade a abelhas, e os de BERAN (1970), o qual verificou que esse composto aplicado em condições de campo na dosagem de $25 \mathrm{~kg}$ i.a. ha ${ }^{-1}$, cerca de 1.041 vezes maior que aquela empregada na presente pesquisa, também foi inofensivo, confirmando seu baixo poder impactante sobre esse grupo de insetos. SANFORD (2003b) e OUTLAW et al. (2006) também classificaram esse composto como inócuo a abelhas adultas. Em relação ao acaricida espirodiclofeno, observou-se que se trata de um produto de baixa toxicidade às abelhas africanizadas. Entretanto, segundo informações contidas em RIEDL et al. (2006) e BAYER (2007), devese evitar o uso desse composto em períodos de florescimento devido ao risco de contaminação de pólen e néctar e da sua toxicidade a populações de abelhas européias. A inocuidade desse acaricida às abelhas africanizadas pode estar relacionada com a hibridação intra-específica, conforme relatado por DANKA et al. (1986), os quais verificaram menor toxicidade de alguns compostos a abelhas híbridas quando em comparação com abelhas européias.

Em relação ao fungicida enxofre, ANDERSON \& ATKINS (1968), ATKINS et al. (1981), HUNT et al. (2003), SANFORD (2003b) e OUTLAW et al. (2006) constataram baixa toxicidade desse composto para abelhas. RIEDL et al. (2006) relataram que os fungicidas geralmente não causam mortalidade de abelhas, uma vez que seus mecanismos de ação estão relacionados ao metabolismo específico de fungos. Porém, de acordo com COLIN \& BELZUNCES (1992), o uso combinado de diferentes classes de produtos, por exemplo, fungicida e inseticida, tais como procloraz e 


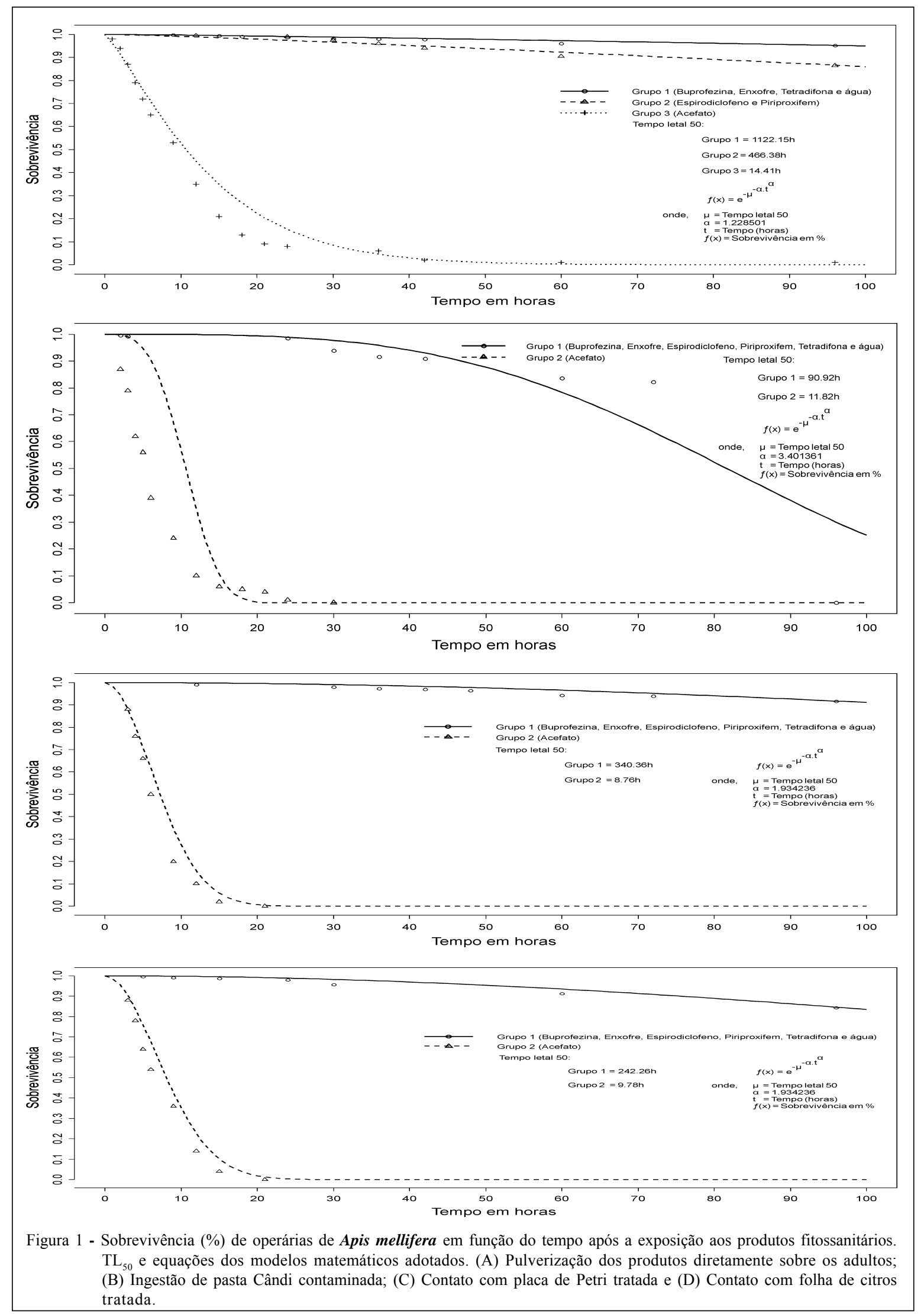

Ciência Rural, v.39, n.4, jul, 2009. 
Tabela 1 - Técnicas de contaminação, grupos de produtos com efeito semelhante, tempo letal 50 (TL $\left.L_{50}\right)$ e modelos matemáticos que explicam os eventos.

\begin{tabular}{lccc}
\hline Técnica & Grupo & $\mathrm{TL}_{50}$ (horas $)$ & Modelos matemáticos \\
\hline Contato com folhas tratadas & 1 & 242,26 & $\mathrm{Y}=\exp \left(\left(-(242.2572)^{\wedge}(-1.934236)\right)^{*}\left(\mathrm{x}^{\wedge} 1.934236\right)\right.$ \\
& 2 & 9,78 & $\mathrm{Y}=\exp \left(\left(-(9.77668)^{\wedge}(-1.934236)\right)^{*}\left(\mathrm{x}^{\wedge} 1.934236\right)\right.$ \\
& 1 & & $\mathrm{Y}=\exp \left(\left(-(340.3587)^{\wedge}(-1.934236)\right)^{*}\left(\mathrm{x}^{\wedge} 1.934236\right)\right.$ \\
Contato com placa tratada & 2 & 340,36 & $\mathrm{Y}=\exp \left(\left(-(8.758284)^{\wedge}(-1.934236)\right)^{*}\left(\mathrm{x}^{\wedge} 1.934236\right)\right.$ \\
& 1 & 8,76 & $\mathrm{Y}=\exp \left(\left(-(90.92182)^{\wedge}(-3.401361)\right)^{*}\left(\mathrm{x}^{\wedge} 3.401361\right)\right.$ \\
Ingestão de pasta Cândi & 2 & 90,92 & $\mathrm{Y}=\exp \left(\left(-(11.82245)^{\wedge}(-3.401361)\right)^{*}\left(\mathrm{x}^{\wedge} 3.401361\right)\right.$ \\
& 1 & 11,82 & $\mathrm{Y}=\exp \left(\left(-(1122.148)^{\wedge}(-1.228501)\right)^{*}\left(\mathrm{x}^{\wedge} 1.228501\right)\right.$ \\
Pulverização direta & 2 & $\mathrm{Y}=\exp \left(\left(-(466.3796)^{\wedge}(-1.228501)\right)^{*}\left(\mathrm{x}^{\wedge} 1.228501\right)\right.$ \\
& 3 & 4122,15 & $\mathrm{Y}=\exp \left(\left(-(14.41112)^{\wedge}(-1.228501)\right)^{*}\left(\mathrm{x}^{\wedge} 1.228501\right)\right.$ \\
\hline
\end{tabular}

deltametrina, pode induzir o sinergismo entre essas moléculas. Quando aplicados conjuntamente em doses subletais, provocaram mortalidade de abelhas superior a $70 \%$ e, quando aplicados de forma isolada, apresentaram mortalidade inferior a $28 \%$.

Efeito do fornecimento de pasta Cândi contaminada sobre A. mellifera

Constatou-se que acefato também foi altamente tóxico às abelhas quando fornecido oralmente, causando a mortalidade de quase todas as abelhas 20 horas após a sua aplicação, com $\mathrm{TL}_{50} \mathrm{de}$ 11,82 horas. CRANE \& WALKER (1983) relataram o alto risco da aplicação desse produto em cultura de citros no período de florescimento, visto que ocasiona contaminação de néctar e de pólen que, ao serem coletados e ingeridos pelas abelhas, podem causar a sua morte ou a de outros espécimes da mesma colônia devido ao comportamento de trofalaxia.

Os produtos piriproxifem, tetradifona, enxofre, espirodiclofeno e buprofezina causaram mortalidade ao redor de $30 \%$ após 96 horas do fornecimento da dieta contaminada e apresentaram $\mathrm{TL}_{50}$ médio de 90,92 horas (Figura 1B, Tabela 1), confirmando relatos de HUNT et al. (2003) e OUTLAW et al. (2006). TASEI (2001) relatou que produtos reguladores de crescimento geralmente são mais prejudiciais aos insetos que se encontram na fase jovem; no entanto, o uso de mimetizadores do hormônio juvenil pode alterar mecanismos biológicos, como, por exemplo, o comportamento e o período de forrageamento, a produção de feromônios e a não-formação da glândula hipofaringial.

Com relação à tetradifona, os resultados obtidos com os adultos de abelhas africanizadas assemelham-se àqueles verificados por SANFORD (2003b) e OUTLAW et al. (2006), os quais o classificaram como inócuo a adultos de $\boldsymbol{A}$. mellifera.

Efeito do contato de A. mellifera com placas de Petri contaminadas

Observou-se também que acefato foi altamente tóxico às abelhas, uma vez que, nas primeiras 20 horas de sua aplicação, causou mortalidade superior a $90 \%$ com $\mathrm{TL}_{50}$ de 8,76 horas. Enxofre, tetradifona, buprofezina, piriproxifem e espirodiclofeno apresentaram menor toxicidade às operárias, com mortalidade, às 96 horas, de $12 \%, 10 \%, 10 \%, 8 \%$ e $4 \%$, respectivamente, e $\mathrm{TL}_{50}$ médio de 340,36 horas (Figura 1C, Tabela 1). O efeito negativo de acefato observado nessa pesquisa confirma os resultados descritos por HUNT et al. (2003), SANFORD (2003b), THOMPSON (2003) e OUTLAW et al. (2006), os quais o classificaram como extremamente nocivo às abelhas. Contudo, JOHANSEN (1977), ao realizar revisão bibliográfica a respeito dos efeitos de produtos fitossanitários sobre polinizadores, relatou que acefato apresenta baixa toxicidade às abelhas, sugerindo sua aplicação antes do florescimento, durante a noite e/ou nas primeiras horas do dia. RIEDL et al. (2006) recomendaram que esse produto não seja aplicado no período de florescimento e, quando seu uso for necessário, que se aguarde um período de segurança de três dias, evitando-se assim o contato das abelhas com os resíduos tóxicos desse composto.

A baixa mortalidade de abelhas provocada pelos inseticidas reguladores de crescimento e pelo acaricida tetradifona assemelha-se aos resultados constatados por HUNT et al. (2003), SANFORD (2003b) e OUTLAW et al. (2006). A inocuidade do fungicida enxofre verificada neste trabalho corrobora as observações feitas por SANFORD (2003b) e RIEDL et 
al. (2006) que o classificaram como atóxico a $\boldsymbol{A}$. mellifera.

Efeito do contato de $\boldsymbol{A}$. mellifera com folhas de citros contaminadas

Em relação a essa técnica de aplicação, verificou-se que o acefato foi altamente tóxico às abelhas africanizadas, uma vez que, 21 horas após o início do contato dos insetos com as folhas contaminadas, causou mortalidade de $100 \%$ dos adultos e apresentou $\mathrm{TL}_{50}$ de 9,78 horas (Figura 1D, Tabela 1). Esses resultados assemelham-se àqueles relatados por HUNT et al. (2003), SANFORD (2003b), THOMPSON (2003) e OUTLAW et al. (2006), que o classificaram como extremamente tóxico às abelhas $A$. mellifera. Segundo DOMINGUEZ et al. (2003), THOMPSON (2003) e GUEZ et al. (2005), além do efeito deletério do acefato quando aplicado em dosagens subletais, pode interferir em processos fisiológicos dos insetos, afetando a capacidade de forrageamento e o desenvolvimento da colônia.

Os produtos enxofre, tetradifona, piriproxifem, espirodiclofeno e buprofezina apresentaram-se inócuos às abelhas, com mortalidades de $22 \%, 18 \%, 16 \%, 10 \%$ e $8 \%$, respectivamente e $\mathrm{TL}_{50}$ médio de 242,26 horas (Figura 1D, Tabela 1). OUTLAW et al. (2006) também relataram que buprofezina, piriproxifem e outros reguladores de crescimento não apresentaram efeitos tóxicos sobre adultos de $\boldsymbol{A}$. mellifera. SANFORD (2003b) classificou o acaricida tetradifona como não-tóxico para abelhas, classificação esta que se aproxima aos resultados constatados no presente trabalho.

De maneira geral, verificou-se um comportamento semelhante das abelhas quando em contato com os produtos fitossanitários; contudo, salienta-se a possível existência de tolerância da abelha africanizada ao acaricida espirodiclofeno.

\section{CONCLUSÕES}

O inseticida acefato foi tóxico para operárias adultas de $\boldsymbol{A}$. mellifera africanizadas independentemente da técnica de aplicação empregada. Os acaricidas espirodiclofeno e tetradifona, os inseticidas reguladores de crescimento piriproxifem e buprofezina e o fungicida enxofre não apresentam efeito tóxico às operárias de $A$. mellifera.

\section{REFERÊNCIAS}

ANDERSON, L.D.; ATKINS, L.E. Pesticide usage in relation to beekeeping. Annual Review of Entomology, v.13, p.213-238,
1968. Disponível em: <http://arjournals.annualreviews.org/loi/ ento?cookieSet=1>. Doi:10.1146/annurev.en.13.010168.001241.

ATKINS, E.L. et al. Reducing pesticides hazardous to honeybees. Mortality prediction techniques and integrated management strategies. Berkeley: University of California, 1981. 20p.

BAYER. Envidor $^{\circledR}$ 240SC Miticide. For control of mites in pome fruit, stone fruit and grapes. Group 23 Acaricide. Calgary, 2007. 13p.

BELZUNCES, L.P. et al. Les phénomènes d'affaiblissement de ruchers. Info Zoo: Bulletin d'Information des Zoologistes de I'INRA, v.6, p.71-75, 1992.

BERAN, F. Our present knowledge on the toxicity and hazard to bees of our pesticides. Gesunde Pflanzen, v.22, p.21-31, 1970 .

COLIN, M.E.; BELZUNCES, L.P. Evidence of synergy between Prochloraz and Deltamethrin in Apis mellifera L.: a convenient biological approach. Pesticide Science, v.36, p.115-119, 1992. Disponível em: <http://www3.interscience.wiley.com/ journal/117935712/grouphome/home.html>. Doi: 10.1002/ ps. 2780360206 .

CRANE, E.; WALKER, P. The impact of pest management on bees and pollination. London: International Bee Research Association, 1983. 129p.

DANKA, R.G. et al. Comparative toxicities of four topically applied insecticides to africanized and European honey bees (Hymenoptera: Apidae). Journal of Economic Entomology, v.79, p.18-21, 1986.

DAVY, M. et al. Risk of Acephate use to the federally listed California Red legged Frog (Rana aurora draytonii). Washington, D.C.: Environmental Fate and Effects Division, 2007. 122p. (Office of Pesticides Programs, 20460).

DECOURTYE, A. et al. Comparative sublethal toxicity of nine pesticides on olfactory learning performances of the honeybee Apis mellifera. Archives of Environmental Contamination and Toxicology, v.48, p.242-250, 2005. Disponível em: <http://www.springerlink.com/content/00904341>. Doi: 10.1007/s00244-003-0262-7.

DEVILLERS, J. et al. Comparative toxicity and hazards of pesticides to Apis and non-Apis bees. A chemometrical study. SAR and QSAR in Environmental Research, v.14, p.389403, 2003. Disponível em: <http://www.ingentaconnect.com/ content/tandf/gsar>. Doi: 10.1080/10629360310001623980.

DeVillers, J.; PHAM-DELEGUE, M.-H. Honey bees: estimating the environmental impact of chemicals. London: Taylor \& Francis, 2002. 332p.

DEVINE, G.J. et al. Insecticide use: contexts and ecological consequences. Agricultural and Human Values, v.24, p.281306, 2007. Disponível em: < http://www.springerlink.com/ content/102841/>. Doi: 10.1007/s10460-007-9067-z.

DOMINGUEZ, V.M.M. et al. Toxicidad sobre Apis mellifera de cebos empleados en el combate de moscas de la fruta. Manejo Integrado de Plagas y Agroecologia, v.69, p.66-72, 2003.

Ciência Rural, v.39, n.4, jul, 2009. 
GUEZ, D. et al. Methyl parathion modifies foraging behaviour in honeybees (Apis mellifera). Ecotoxicology, v.14, p.431437, 2005. Disponível em: <http://www.springerlink.com/ content/0963-9292>. Doi: 10.1007/s10646-004-1348-3.

HUNT, G. et al. Protecting honey bees from pesticides. Beekeeping: Purdue University Cooperative Extension Service, 2003. 8 p.

JOHANSEN, C.A. Pesticides and pollinators. Annual Review of Entomology, v.22, p.177-192, 1977. Disponível em: <http:/ /arjournals.annualreviews.org/loi/ento? cookieSet $=1>$. Doi:10.1146/annurev.en.22.010177.001141.

MALERBO-SOUZA, D.T. et al. Polinização em cultura de laranja (Citrus sinensis L. Osbeck, var. Pera-Rio). Brazilian Journal of Veterinary Research and Animal Science, v.40, p.237242, 2003. Disponível em: <http://www.scielo.br/ scielo.php?script=sci serial\&pid=1413-9596\&lng=en\&nrm=iso. Doi: $10.1590 / \mathrm{S} 1413-95962003000400001$.

OUTLAW, T.E. et al. How to protect honeybees from pesticides. Clemson: Clemson University. Department of Pesticides Regulation, 2006. 4p.

R DEVELOPMENT CORE TEAM. R: a language and environment for statistical computing. Vienna, Austria: R Foundation for Statistical Computing,. 2008. (ISBN 3-90005107-0). Acesso em: janeiro 2008, Disponível em: http://www.Rproject.org.

RIEDL, H. et al. How to reduce bee poisoning from pesticides. Oregon: A Pacific Northwest Extension, 2006. 28p. (PNW 591).

RIGitanO, R.L.O.; CARVALHO, G.A. Toxicologia e seletividade de inseticidas. Lavras: FAEPE, 2001. 72p.
ROBINSON, P. Evaluation of the new active Buprofezin in the product applaud insecticide. Canberra, Australia: National Registration Authority for Agricultural and Veterinary Chemicals, 2001. 59p.

SANFORD, M.T. Pollination of citrus by honey bees Florida: University of Florida, Cooperative of Extension Service, 2003a. 8p.

SANFORD, M.T. Protecting honey bees from pesticides. Florida: University of Florida, Cooperative of Extension Service, 2003b. 21p.

STONER, A. et al. Acephate (Orthene): Effects on honey bee queen, brood and worker survival. American Bee Journal, v. 125, p.448-450, 1985.

TASEI, J.N. Effects of insect growth regulators on honey bees and non-Apis bees. a review. Apidologie, v.32, p.527-545, 2001. Disponível em: <http://www.apidologie.org/>. Doi: 10.1051/apido:2001102.

THOMPSON, H.M. Behavioral effects of pesticides in bees their potential for use in risk assessment. Ecotoxicology, v.12, p.317-330, 2003. Disponível em: <http:/www.springerlink.com/ content/0963-9292>. Doi: 10.1023/A:1022575315413.

VANDAME, R. et al. Alteration of the homing-flight in the honey bee Apis mellifera L. exposed to sublethal dose of deltamethrin. Environmental Toxicology and Chemistry, v.14, p.855-860, 1995. Disponível em: <http://www.setacjournals.org/perlserv/ ?request $=$ get-toc $\&$ issn $=1552-8618 \&$ volume $=28 \&$ issue $=2>$. Doi: 10.1897/1552-8618(1995)14[855:AOTHIT]2.0.CO;2

WIESE, H. Apicultura - novos tempos. 2.ed. Porto Alegre: Agrolivros, 2005. 378p. 